\section{Moving beyond discourse? A response to Jan Slaby}

\author{
Stacey Smith
}

On a gloomy Tuesday last year, I waited over an hour in the London rain to see Albert Einstein's brain in a jar. Afterwards, I sat in the gift shop of the Wellcome Trust museum to read a magazine (there was an article on male versus female minds which caught my feminist eye) surrounded by people eating their so-called superfoods and guzzling on 'neuro' juices. In the background was the underlying hum of static electricity as children played the latest 'brain training' games on their Nintendos. Although this example may not be typical, it certainly isn't difficult to see how neuroscience has become a major part of the public imaginary. This is why Jan Slaby and his 'critical neuroscience' initiative is so important, because it seeks to analyse the ways in which human behaviours and/or the biological categorisation of people have become 'naturalised' or taken for granted. ${ }^{1}{ }^{2}$ In an attempt to move away from the culture of 'hope and hype' in the biosciences, ${ }^{3}$ the critical neuroscience approach involves a concentrated attentiveness to language, looking to the politics behind the allure of the brain image, questioning why certain ideas have become popularised and evaluating where cultural representations of scientific concepts have emerged. This is reminiscent of Michel Foucault's genealogical method, so is no surprise that Slaby champions Rajan's governmentality framework ${ }^{4}$ for analysing life and capital. Although this method serves Slaby's purpose of providing a macro-level style of critique of the neurosciences, what is vitally missing for me is an acknowledgement of difference, a recognition of the nuances that exist in this (ever expanding) field, personal experience and the value of experimentation. Where Slaby argues we should be 'wary' of interdisciplinary endeavours, I also advocate a cautionary stance-against the easy assumptions of loss which frequently mark critical theory. Instead, I ask what is to be gained? How can we in the humanities, adopt an affirmative stance while still remaining critical? This is a

Correspondence to Stacey Smith, School of Geographical Sciences, University of Bristol, University Road, Bristol BS8 1SS, UK; Stacey.smith@bristol.ac.uk challenge, certainly, but much more of an exciting venture.

Instead of focusing on the metadiscourses of neuroscience (which evokes an immediate air of academic cynicism), I am more interested in what is happening in practice, in real-life, for different people in different spaces, or to use Isabelle Stengers' words, switching to the 'minor key'. To operate in the minor key means to 'slow down' reasoning, ${ }^{5}$ leaving room for pause or refrain. This allows for more reflective thought for identifying which questions matter-'How to learn?', Stengers asks, 'how to pay attention? How to acquire new habits of thinking? How to concentrate or explore other kinds of experiences?' ${ }^{2}$ Through a top-level style of critique there is a danger of underestimating the complexities of neuroscience because the types of 'conditions' to be analysed are almost pre-determined: macrostructures, institutional guidelines, popularisation, public discourse and the bioeconomy to name a few. That is not to say these things do not matter, far from it; thinking in the minor does not mean to dismiss the major, for the 'central stage' upon which the minor performs is obviously affected by political elements. No practice is independent of its environment, but 'this empathically does not mean that the identity of a practice may be derived from its environment'. ${ }^{6}$ In a similar vein, medical humanities scholars Felicity Callard and Des Fitzgerald ${ }^{7}$ call for an attention to the 'experimental entanglements' between neuroscientific and sociocultural knowledges which recognises how they are enacted in practice. They argue that to examine the intersections between neuro and social sciences, a focus on the experimental spaces may encourage an openness to methodological novelty, a recognition of the dynamism and complexity of research and importantly, allow joy and play in our enquiries. They also importantly point out that although much critical (and necessary) work has been done on the conceptual implications of the rise of neuroscience, what is missing are crucial questions on what this might mean methodologically. What is at stake when we move away from dialogue? What can we learn through 'untidiness, excess and chance'? ${ }^{7}$
Let me share an example. I was conducting research in an NHS hospital on a clinical trial for brain injury patients. The neuroscientists were using novel fMRI techniques to distinguish whether a patient was in a vegetative state or minimally conscious state. There was a lot at stake, for if the patient was diagnosed as minimally conscious, they would qualify for highly specialised rehabilitative carewhich was expensive and not readily available. In order to be deemed 'conscious' in the study, the patient had to exhibit signs of following a command. I was told a story of a patient (let's call him patient X) who did not respond to any language function tests. At the time, the team came to two possible conclusions-it could either be that his head was moving too much to capture anything valuable, or he was indeed in a vegetative state. The patient's father was in the control room at the time and became upset. He grabbed the microphone and pleaded with his son to talk. Upon hearing his voice, the patient began to move. When the father stopped speaking and they went back to the tape, the patient stopped moving.

But here, watching it, it was so clearly correlated that we couldn't just let it go. Our rehab consultant just told everyone to stop. I don't know what happened, perhaps the patient's love for his father was shining through more than his desire to talk to us. I know that's corny but you never know how the brain will respond. After that we realised we had to interrogate the data for the individual and tailor our experiment. (Interviewed computer scientist)

The protocol of an fMRI experiment is usually to disregard any movement to minimise error, but if the neuroscientists had done that, patient $\mathrm{X}$ would have been left behind. This opened up a previously very closed space, one dictated by protocol, measurement and paradigms, into a space of possibility and hope. This example also demonstrates that to remain truly critical, the fact that it 'could have been otherwise' must always be kept in mind. For this, we must continually revisit and reflexively examine the sets of assumptions that inform our understandings. Call me optimistic, but I wonder if neuroscientists at many other sites across the world were more open to alternative explanations than some commentators give them credit for, or did indeed recognise their institutional restraints and included things like affect and familial relations into their analyses, what might critique look like then? There is much 
more room for manoeuvre than perhaps Slaby allows in his piece. ${ }^{2}$ To begin with 'loss' automatically hinders our analysis because it constructs barriers between social and the life sciences. To quote geographer Derek McCormack, 'that is not to suggest that in the effort to attend to [molecular] affect, those in the social sciences need to become quasineuroscientists with a penchant for meditation' but be more open to the possibility that the kinds of stories told by various neuroscientists 'might usefully compliment the ways in which social scientists produce accounts of affective materialities constituted in these spaces'. 8 Hope and human agency are deeply and immediately embedded in real medical and healthcare practices which are not so easily captured. I believe the humanities is in a unique position to do this, and while there is a legitimate concern for caution, we should not be fearful.

Twitter Follow Stacey Smith at @stacey_smith88

Competing interests None.

Provenance and peer review Not commissioned; internally peer reviewed.

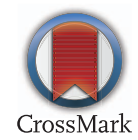

To cite Smith S. Med Humanit 2015;41:23-24.

Received 10 March 2015

Accepted 11 March 2015

\section{(5) Linked}

http://dx.doi.org/10.1136/medhum-2015-010677

Med Humanit 2015;41:23-24.

doi:10.1136/medhum-2015-010702

\section{REFERENCES}

1 Slaby J, Choudhury S. Proposal for a critical neuroscience. In: Choudhury S, Slaby J, eds. Critical neuroscience: a handbook of the social and cultural contexts of neuroscience. Chichester: Wiley-Blackwell, 2012:29-51.

2 Slaby J. Critical neuroscience meets humanities. Med Humanit 2015;41:16-22.

3 Rose N. The politics of life itself: biomedicine, power, and subjectivity in the twenty-first century. Princeton: Princeton University Press, 2007:100.

4 Rajan KS. Biocapital: the constitution of postgenomic life. Durham: Duke University Press, 2006.

5 Stengers I. The cosmopolitical proposal. In: Latour B, Weibel P, eds. Making things public: atmospheres of democracy. Cambridge: MIT Press, 2005:994.

6 Stengers I. The challenge of complexity: unfolding the ethics of science. In memoriam llya Prigogine. E:CO 2004;6(1-2):92-9.

7 Fitzgerald D, Callard F. Social science and neuroscience beyond interdisciplinarity: experimental entanglements. Theory Cult Soc 2014:1-30.

8 McCormack D. Molecular affects in human geographies. Environ Plan A 2007;39:359-77. 